\title{
1 Oil-in-water microemulsion containing ferrocene: A new fire suppressant
}

3 Yusuke Koshiba ${ }^{\mathrm{a}, *}$, Takuya Tomita ${ }^{\mathrm{b}}$, Hideo Ohtani ${ }^{\mathrm{c}}$

4

$5 \quad{ }^{a}$ Department of Materials Science and Chemical Engineering, Faculty of Engineering, Yokohama

6 National University, 79-5 Tokiwadai, Hodogaya-ku, Yokohama 240-8501, Japan

$7 \quad{ }^{\mathrm{b}}$ Graduate school of Environmental and Information Sciences, Yokohama National University, 79-7

8 Tokiwadai, Hodogaya-ku, Yokohama 240-8501, Japan

$9{ }^{\mathrm{c}}$ Department of Safety Management, Faculty of Environmental and Information Sciences,

10 Yokohama National University, 79-7 Tokiwadai, Hodogaya-ku, Yokohama 240-8501, Japan

11

12

* Corresponding author: Telephone number: +81 453393985

13

Fax number: +81453393985

E-mail addresses: ykoshiba@ynu.ac.jp, koshiba-yusuke-xm@ynu.ac.jp

240-8501, Japan 


\section{$1 \quad$ Abstract}

2 This paper reports the preparation and fire-suppression efficiency of oil-in-water microemulsions

3 containing ferrocene. In this work, oil-in-water emulsions containing 0-1,000 ppm ferrocene and four

4 surfactants (Surfynol 465, Olfin E1020, Triton X-100 (TX), and Noigen TDS-80 (NT)) were prepared

5 by homogenizing n-octane solutions of ferrocene and aqueous surfactant solutions at ambient

6 temperature. Four emulsion parameters were then characterized: emulsion stability, oil-droplet size in

7 emulsion, flash point, and capability of extinguishing n-heptane pool fires. Emulsion stability

8 experiments and droplet-size measurements clearly demonstrated that the oil-in-water emulsions

9 containing ferrocene and TX/NT were thermodynamically stable microemulsions. Flash-point

10 measurements confirmed that no oil-in-water microemulsions tested ignited below $93{ }^{\circ} \mathrm{C}$. Suppression

11 trials involving microemulsions containing $0-1,000 \mathrm{ppm}$ ferrocene and NT revealed the relationship

12 between their fire suppression efficiency and the concentrations of ferrocene and NT, and also

13 demonstrated that the microemulsions tested in this study have a higher ability to suppress pool fires compared with a conventional wet chemical agent.

16 Keywords: Fire suppression; Ferrocene; Oil-in-water microemulsion; Phosphorus free; Fire-

17 extinguishing agent; Water mist; Noigen TDS-80 (Lutensol TO 89); Surfactant; Extinguishment; Pool

18 fire 


\section{Abbreviations}

3 ANOVA

$4 \quad \mathrm{Bu}$

$5 d$

$6 \quad F$

$7 \quad \mathrm{FeCp}_{2}$

$8 H A$

$9 \quad H E$

10 HMIS

$11 \quad H O$

$12 \mathrm{Me}$

$13 \quad \mathrm{ME}$

$14 \quad \mathrm{ME}_{\mathrm{NT}}(x, y)$

$15 \quad \mathrm{ME}_{\mathrm{TX}}(x, y)$

$16 n$

$17 \quad$ NFPA

$18 \quad$ NT
Analysis of variance

Butyl

Droplet diameter (nm or $\mu \mathrm{m})$

F value (also called F statistic; dimensionless)

Ferrocene

Height of an aqueous layer (mm)

Total height of the emulsion $(\mathrm{mm})$

Hazardous Materials Identification System

Height of an oil layer (mm)

Methyl

Microemulsion

Microemulsion containing NT, $x$-wt $\%$ oil, and $y$-ppm ferrocene

Microemulsion containing TX, $x$-wt $\%$ oil, and $y$-ppm ferrocene

Number of droplets (dimensionless)

National Fire Prevention Association

Noigen TDS-80 
1 OE Olfin E1020

$2 \mathrm{O} / \mathrm{W} \quad$ Oil-in-water

$3 \quad p \quad$ Probability, p-value (dimensionless)

$4 \quad P S \quad$ Phase separation (vol\%)

$5 \quad R \quad$ Weight ratio of n-octane to surfactant (dimensionless)

$6 \quad S M D \quad$ Sauter mean diameter $(\mathrm{nm}$ or $\mu \mathrm{m})$

$7 \quad$ SN $\quad$ Surfynol 465

8 Soln. Aqueous solution

9 TX Triton X-100

10 USD U.S. dollar

$11 \quad W \quad$ Weight $(\mathrm{g})$

12

13 Greek characters

$14 \sigma \quad$ Standard deviation of extinguishing times (s)

$15 \tau \quad$ Average extinguishing time (s)

16

$17 \quad$ Subscripts

$18 \mathrm{~m} \quad$ Mist 


$\begin{array}{lll}1 & \text { ME } & \text { Microemulsion } \\ 2 & \text { NT } & \text { Noigen TDS-80 } \\ 3 & \text { o } & \text { Oil } \\ 4 & \text { oct } & \text { n-octane } \\ 5 & \text { surf } & \text { Surfactant } \\ 6 & \text { TX } & \text { Triton X-100 } \\ 7 & & \\ 8 & \text { Superscripts } \\ & & \\ 9 & i & \text { iso- } \\ 10 & t & \text { tert- }\end{array}$

12 1. Introduction

14 Accidental fires are disaster that can lead to human suffering, property losses, and environmental

15 damage. Thus, they are an important social issue in most countries; for instance, fires in the United

16 States and Japan still claimed the lives of 3,275 and 1,675 people in 2014, respectively. In many

17 situations, containing and extinguishing a small developing fire with handheld fire extinguishers is of

18 great importance. Developing more effective fire suppressants is, therefore, of considerable help in 
1 reducing such fire-related casualties. Nowadays, phosphates and their derivatives are widely used as

2 fire-extinguishing agents [1,2]. As is well known, phosphorus is one of the three major nutrients in

3 crop production. As shown in Fig. 1, owing to recent global problems involving nonrenewable

4 phosphate rock such as future scarcity and dramatically increased costs [3,4], developing not only

5 efficient phosphorus recycling and recovery techniques [5] but also alternatives for phosphorus-based

6 fire suppressants are required at present.

7 Water-mist technology has received increasing attention because of its low-cost, ubiquity, and

8 environmentally friendly properties. It is known that the major mechanisms through which water mist

9 extinguishes fires involve the removal of heat in the flame zone (or fuel surface), attenuation of thermal

10 radiation, and displacement of oxygen [6]. Additives to water are often required to further enhance its

11 suppression capability and these typically include surfactants [7], antifreezes [8], and metallic

compounds. Several transition metals have the ability to catalytically scavenge radicals involved in

13 the gas-phase chain reactions. They exhibit various oxidation states, which means that transition-metal

compounds can potentially behave as flame inhibitors. Of all the transition-metal compounds,

ferrocene ( $\mathrm{FeCp}_{2}$, Fig. 2a), an organo-iron compound, is a novel promising flame inhibitor due to its

16 high radical-trapping capability $[9,10]$; ferrocene and its derivatives are applied in related areas as

17 smoke suppressants and flame retardants [11-14]. Despite its excellent extinguishing properties, using

18 ferrocene as an additive in water poses two problems: strong fraction-dependency of fire-suppression 
1 efficiency and insolubility in water. The former reflects the fact that the ability to suppress a flame

2 dramatically decreases at lower and higher ferrocene fractions, i.e., an optimum amount of ferrocene

3 must be introduced into a flame. The latter means that it is difficult to directly add ferrocene (as-is) in

4 water because of its high lipophilicity. Koshiba and co-workers reported a ferrocene-containing water-

5 based fire suppressant: aqueous ferrocene dispersions having an optimum ferrocene concentration

6 using dispersion techniques $[15,16]$. The earlier studies clearly demonstrated that (i) aqueous

7 dispersions containing smaller ferrocene particles exhibit higher dispersibilities and that (ii) the fire-

8 extinguishing capabilities of ferrocene dispersions are positively correlated with their dispersibility.

9 However, they also revealed that the dispersibility steeply decreases in a short time, potentially

10 resulting in a decrease in their suppression ability. In addition, directly dispersing organometallic

11 ferrocene powder in water may cause the ferrocene to degrade, so that ferrocene dispersions eventually

12 break down. To solve these issues, Koshiba and co-workers recently proposed a new ferrocene-

13 containing emulsion-based fire suppressant: a ferrocene-containing emulsion [17]. This emulsion

14 technique involves dissolving ferrocene in oil and then dispersing the solution in an aqueous medium

15 using surfactants. Unfortunately, however, this earlier study only reported one emulsion system.

16

By definition, oil-in-water (O/W) "macroemulsions" are heterogeneous, opaque, and

17 thermodynamically unstable systems in which oil droplets will coalesce, eventually leading to phase 
1 macroscopically homogeneous and thermodynamically stable systems; they also have some

2 distinguishing physicochemical properties: optical transparency, isotropy, and low viscosity [18]. The

3 present work focuses on the fire-suppression capability of ferrocene-containing microemulsions. The

4 major advantages of using microemulsion techniques are as follows:

5

6

- The dispersibility, which is positively correlated with the suppression capability as stated above,

7 would be dramatically improved if thermodynamically stable ferrocene-containing

8 microemulsions can be formed.

9

- Oil-in-water microemulsions have nano-sized oil droplets in which molecular ferrocene dissolves.

10 The extinguishing efficiency is typically enhanced as the particle size of a suppressant decreases

11 [19]. Hence, ferrocene-containing microemulsions would have higher extinguishing efficiency

12 compared with aqueous dispersions containing micron-sized ferrocene particles.

- Dissolving organometallic ferrocene in the oil phase may prevent its direct reaction with water and subsequent decomposition.

The present study aims to prepare new, phosphorus-free, stable n-octane/water microemulsions

17 containing surfactants and ferrocene, and to experimentally elucidate their fire-suppression 
1 E1020 (OE), Noigen TDS-80 (NT, also known as BASF Lutensol TO 89), and Triton X-100 (TX), as

2 depicted in Fig. 2b-e. These surfactants having low critical micelle concentrations are used in various

3 applications including life-, food-, and material sciences [20-22] because, for instance, Surfynol 465

4 complies with Food and Drug Administration and Environmental Protection Agency regulations and

5 Noigen TSD-80 exhibits high biodegradability. In general, varying the surfactant used in the solution

6 will modify the emulsion stability [23], possibly improving the fire-extinguishing efficiency. The

7 stability of the ferrocene-containing $\mathrm{O} / \mathrm{W}$ emulsions was determined using a phase separation method

8 [24]. In the suppression experiments, an n-octane/NT/water emulsion system in which no phase

9 separation had occurred was evaluated for its ability to extinguish pool fires.

\section{Materials and Methods}

\subsection{Chemicals}

Ferrocene (purity $>98.0 \%$ ) was purchased from Sigma-Aldrich Co., USA and used without further

purification. Water was used after deionization. To form ferrocene-containing $\mathrm{O} / \mathrm{W}$ microemulsions,

17 four nonionic surfactants were employed: SN, OE, NT, and TX, as described above. Dry n-octane

18 (purity $>98.0 \%$ ) was employed because of its high ferrocene solubility at room temperature [17]. 
4 Ferrocene-containing $\mathrm{O} / \mathrm{W}$ emulsions were prepared by thoroughly homogenizing n-octane

5 solutions of ferrocene and aqueous surfactant solutions at room temperature for $15 \mathrm{~min}$ at $5000 \mathrm{rpm}$

6 using a homogenizer (T18, IKA, USA). When the concentration of n-octane is set to $2.1 \mathrm{wt} \%$, the $\mathrm{O} / \mathrm{W}$

7 emulsions can have a ferrocene content of up to $1000 \mathrm{ppm}$ on a mass/mass basis. In this study, the

8 weight ratio of n-octane to the surfactant, $R$, was varied between $R=1.0$ and $R=5.0$ [17].

9

10

$$
R=\frac{W_{\text {surf }}}{W_{\text {oct }}}
$$

where $W_{\text {surf }}$ and $W_{\text {oct }}$ are the weights of the surfactant and n-octane, respectively.

\subsubsection{Emulsion Stability}

O/W macroemulsions generally exhibit poor stability when used without any amphiphile (e.g.,

surfactant). The phase separation of $\mathrm{O} / \mathrm{W}$ macroemulsions is triggered by several destabilization 
1 mechanisms: creaming, sedimentation, flocculation, and Ostwald ripening [25]. Such destabilization

2 causes irreversible coalescence of oil droplets, eventually leading to phase separation. As described

3 previously, emulsion instability would reduce its extinguishing capability; in addition, unstable

4 emulsions may be flammable, since the oil tends to concentrate in the upper layers of the mixture as a

5 result of the density difference between the phases (density of n-octane: $0.70 \mathrm{~g} / \mathrm{cm}^{3}<$ density of water:

$6 \quad 1.00 \mathrm{~g} / \mathrm{cm}^{3}$ at $20^{\circ} \mathrm{C}$ ). Hence, evaluating emulsion stability is of great importance in this study.

7 Typical techniques for determining emulsion stability include zeta potential, nuclear magnetic

8 resonance, and light scattering methods [26,27]. In this study, the emulsion stability was simply

9 evaluated using the phase separation method [28]. $100 \mathrm{~mL}$ of each fresh, uniform emulsion was poured

10 into flat-bottomed glass test tubes ( $35 \mathrm{~mm}$ in diameter and $125 \mathrm{~mm}$ in length) so as not to foam, and

11 then the test tubes were capped and conditioned at $25^{\circ} \mathrm{C}$ in a thermostatic chamber. The gravity-

induced phase separation was monitored for a long period ( 25 months) by measuring the amounts of

$$
P S=\frac{100 \cdot H O}{H E}=\frac{100 \cdot H O}{H A+H O},
$$


1 the aqueous layer.

The oil-droplet size in emulsions remarkably affects their appearance, reactivity, rheology, color, and stability [29,30]. Besides these physicochemical properties, the size of oil droplets containing

6 ferrocene probably dominates the fire-extinguishing efficiency due to the particle-size dependency of

7 the suppression ability, as stated above [19]. Hence, it is essential to gain an insight into the oil-droplet

8 size distribution. In this study, the droplet-size distribution of the prepared $\mathrm{O} / \mathrm{W}$ microemulsions was

9 measured at $25^{\circ} \mathrm{C}$ using a dynamic light scattering instrument (ELS-Z 2, Otsuka Electronics, Co. Ltd.,

10 Japan), and the mean oil-droplet size was expressed as the Sauter mean diameter (SMD) by the

11 following equation:

$$
S M D=\frac{\sum n_{i} d_{i}^{3}}{\sum n_{i} d_{i}^{2}},
$$

where $n_{\mathrm{i}}$ is the measured number of droplets with diameter $d_{\mathrm{i}}$.

As described above, the $\mathrm{O} / \mathrm{W}$ emulsions tested in this study contained n-octane (flash point: $13^{\circ} \mathrm{C}$, 
1 [31]). We cannot use the $\mathrm{O} / \mathrm{W}$ microemulsions as fire suppressants if they are highly flammable at

2 ambient temperature. In this study, the flash points of the $\mathrm{O} / \mathrm{W}$ emulsions were determined using a

3 Tag closed-cup tester (TAG-E, Yoshida Kagaku Kaisha Co., Ltd., Japan) according to a standard test

4 method [32].

5

$6 \quad$ 2.3.4 Suppression Experiments

7 Before conducting the suppression trials, the spray droplets, which strongly govern the

8 extinguishing efficiency, were measured using the immersion technique [33]. This method involves

9 gathering spray droplets with an immiscible liquid (e.g., silicone oil), and then directly making

10 microscopic observations of the droplet size (DMI 2000B, Leica, Germany). Note that the droplet size

11 may change depending on the measuring methods, such as phase Doppler, laser diffraction, freeing,

12 photographic, and immersion methods [33]. Nevertheless, as mentioned later, the oil-droplet size of

13 the $\mathrm{O} / \mathrm{W}$ microemulsions used in this study was three orders of magnitude smaller than the spray

14 droplet, implying that the spray mist probably comprises emulsion droplets.

Fig. 3 illustrates the experimental apparatus used for the suppression trials, which was built to

16 simply elucidate the ability to suppress pool fires. $80 \mathrm{~mL}$ of n-heptane was poured into an $83 \mathrm{~mm}$ -

17 diameter pan, which was placed $600 \mathrm{~mm}$ below a nozzle. After a quasi-steady burning rate was

18 achieved (i.e., preburning), the nozzle was activated at a flow rate of $300 \mathrm{~mL} / \mathrm{min}$. The spray angle 
1 was $50^{\circ}$. The average extinguishing time $(\tau)$ and its standard deviation $(\sigma)$ were determined from ten

2 trials for each microemulsion.

3

4 3. Suppression Mechanisms

5

6

Fig. 4 presents a schematic model of the suppression mechanisms by the ferrocene-containing $\mathrm{O} / \mathrm{W}$

7 microemulsions. When $\mathrm{O} / \mathrm{W}$ microemulsion droplets are sprayed onto fires, micron-sized water

8 droplets and ferrocene-containing nano-sized oil droplets readily evaporate, releasing ferrocene

9 molecules into the flames. As described above, ferrocene readily decomposes and breaks down to

10 produce active iron species, such as $\mathrm{FeO}, \mathrm{FeOH}, \mathrm{Fe}$, and $\mathrm{Fe}(\mathrm{OH})_{2}$ [34]. Several numerical and

11 experimental studies have reported that the suppression efficiency of iron compounds is sensitive to

12 the concentrations of the iron species. [10,16]. Below superequilibrium concentrations, iron-catalyzed

13 radical recombination is not effective at trapping radicals; in contrast, a very high concentration of

14 iron species acts as a trigger for lowering the suppression efficiency owing to the condensation and

15 agglomeration of the active iron species among themselves. This implies that an optimum

16 concentration of ferrocene should be added into the flames. Ferrocene-based fire-extinguishing agents

17 are promising candidates due to their low optimum ferrocene concentrations and high extinguishing

18 efficiencies. 


\section{Results and Discussion}

3

6 The time required for the phase separation of the $\mathrm{O} / \mathrm{W}$ emulsions containing $1000 \mathrm{ppm}$ ferrocene

7 and $\mathrm{SN} / \mathrm{OE}$ was short (SN: $<30 \mathrm{~min}, \mathrm{OE}:<20 \mathrm{~min}$ ). This result and the fact that the $\mathrm{O} / \mathrm{W}$ emulsions

8 were opaque imply that they were macroemulsions.

Fig. 5 shows the variations of the phase separation of the O/W emulsions containing 1000-ppm

10 ferrocene and the surfactant as a function of storage time at $25{ }^{\circ} \mathrm{C}$ (Fig. $5 \mathrm{a}$ : surfactant $=\mathrm{NT}$, Fig. $5 \mathrm{~b}$ :

11 surfactant $=\mathrm{TX})$. Note that the $P S$ value is given in terms of vol\%. In this figure, the more unstable emulsions exhibited higher phase separation values and no phase separation was observed when $P S=$

0 . For the NT-containing O/W emulsions with $R_{\mathrm{NT}} \leq 3.0$ (Fig. 5a), the emulsion phases rapidly separated within $180 \mathrm{~min}$, whereas no phase separation was observed at $R_{\mathrm{NT}} \geq 3.5$ for at least 25 months. As depicted in Fig. 5b, for O/W emulsions containing TX, phase separation occurred within $180 \mathrm{~min}$ at $R_{\mathrm{TX}}=2.0-4.0$; however, we confirmed that phase separation did not occur for the $\mathrm{O} / \mathrm{W}$ emulsion with $R_{\mathrm{TX}}=5.0$ for at least 25 months.

Fig. 6a shows a digital photograph of the $\mathrm{O} / \mathrm{W}$ emulsions (surfactant $=\mathrm{NT}$ and $R_{\mathrm{NT}}=3.5$ ). In this 
1 figure, the emulsions containing 100, 500, and $750 \mathrm{ppm}$ ferrocene are in the left, center, and right Petri

2 dishes (93 $\mathrm{mm}$ in diameter and $15 \mathrm{~mm}$ in height), respectively. Fig. $6 \mathrm{~b}$ presents the appearance of the

$3 \mathrm{O} / \mathrm{W}$ emulsions (surfactant $=\mathrm{TX}$ and $R_{\mathrm{TX}}=5.0$ ). In this figure, the emulsions containing 100, 500,

4 and 1,000 ppm ferrocene are in the left, center, and right Petri dishes, respectively. All the emulsions

5 depicted in these figures were completely transparent for at least 25 months at room temperature; the

6 yellow coloration was due to ferrocene itself. The fact that these $\mathrm{O} / \mathrm{W}$ emulsions were transparent and

7 stable over long periods indubitably indicates that they are microemulsions. Fig. $6 \mathrm{c}$ shows the O/W

8 emulsion containing $100 \mathrm{ppm}$ ferrocene and NT $\left(R_{\mathrm{NT}}=1.0\right)$, in which phase separation readily

9 occurred as noted above. In this case when $R_{\mathrm{NT}}=1.0$, the solution is undoubtedly an opaque

10 macroemulsion.

\subsection{Emulsion Droplet-Size Distribution}

In this section, the Sauter mean diameters of the stable O/W "microemulsions" containing NT and

TX are discussed. Hereafter, the microemulsion containing NT, $x \mathrm{wt} \%$ oil, and $y$-ppm ferrocene is

16 referred to as "ME $\mathrm{NT}_{\mathrm{NT}}(x, y)$," and the corresponding microemulsion containing TX is referred to as "ME $E_{\mathrm{TX}}(x, y) . "$

Table 1 lists the Sauter mean diameters of the oil droplets $\left(S M D_{\mathrm{o}}\right)$ for the microemulsions 
1 containing $2.1 \mathrm{wt} \% \mathrm{n}$-octane, $0-1,000 \mathrm{ppm}$ ferrocene, and the surfactant (NT or TX). The weight ratios

2 of n-octane to the surfactants (NT and TX) were $R_{\mathrm{NT}}=3.5$ and $R_{\mathrm{TX}}=5.0$. As seen in the table, the oil-

3 droplet sizes averaged $\sim 10 \mathrm{~nm}$. In general, microemulsions have droplets with diameters of

4 approximately $10-50 \mathrm{~nm}$ [25]; the transparency of microemulsions is attributed to nano-sized droplets,

5 which are significantly smaller than the visible wavelengths of light. The observation of droplet sizes

6 of ca. $10 \mathrm{~nm}$ also provides evidence of the formation of microemulsion systems. For the

7 microemulsions containing NT, it is clear that there is no significant difference in the oil-droplet size

8 for different ferrocene concentration $(0-1,000 \mathrm{ppm})$; the same is true for the microemulsions

9 containing TX. This result indicates that, in the ferrocene concentration range of $0-1,000 \mathrm{ppm}$, the

10 ferrocene concentration has little influence on the Sauter mean diameter of the oil droplet in the

11 microemulsion system. In addition, no significant difference in terms of the $S M D_{\mathrm{o}}$ values was observed

12 between NT- and TX-containing microemulsions; thus, the influence of the oil-droplet size on the fire-

13 extinguishing efficiency is negligible.

17 The Tag closed-cup tests revealed that no microemulsions tested in this study ignited below $93^{\circ} \mathrm{C}$.

18 This is because the concentration of n-octane was too low to ignite the microemulsion, thus 
1 demonstrating that the microemulsions pose little ignition risk during handling and storage. Although

2 the surfactants, experimental conditions, and fuel concentrations were not identical, the results of this

3 study are consistent with the finding of Lee et al. that n-octane/water emulsions have very low flame

4 propagation velocities, even at an n-octane concentration of $80 \mathrm{vol} \%$ in emulsions [35].

5

$6 \quad 4.4$ Suppression Experiments

7

8 In this section, the pool-fire extinguishing ability of the microemulsions containing NT is

9 investigated. The reason for this investigation is that this study aimed to directly and simply evaluate

10 the influence of ferrocene on the extinguishing capability of microemulsions; for the microemulsions

11 containing TX, we observed some foaming that positively affects the suppression efficiency. Table 2

12 presents all the samples tested in extinguishing trials, including an aqueous solution of NT (hereafter

13 referred to as NT soln.), the microemulsions, and a wet chemical agent. Typical photographs of fire

14 suppression by pure water mist and $\operatorname{ME}_{\mathrm{NT}}(2.1,750)$ are shown in Fig. 7.

\subsubsection{Influence of oil concentration on extinguishing time}

17 As described above, the microemulsions used in this work contained a small amount of flammable

18 oil used for dissolving ferrocene. Hence, the suppression effects of ferrocene must surpass the 
1 flammability of the oil in the system. In this subsection, the influence of the oil amount on the

2 suppression efficiency was investigated. The suppression trials were performed at a constant ferrocene

3 concentration of $100 \mathrm{ppm}$ and n-octane concentrations ranging from $2.1 \mathrm{wt} \%$ to $10.5 \mathrm{wt} \%$.

4 The extinguishing times for $\operatorname{ME}_{\mathrm{NT}}(2.1,0), \mathrm{ME}_{\mathrm{NT}}(2.1,100), \mathrm{ME}_{\mathrm{NT}}(4.2,100)$, and $\mathrm{ME}_{\mathrm{NT}}(10.5$,

$5100)$ are graphed in Fig.8. $\mathrm{ME}_{\mathrm{NT}}(2.1,0)$ had an average extinguishing time of ca. $21 \mathrm{~s}$. As expected,

6 the extinguishing time of $\mathrm{ME}_{\mathrm{NT}}(2.1,100)$ was reduced by a factor of approximately 2.5 , compared

7 with that of $\operatorname{ME}_{\mathrm{NT}}(2.1,0)$ by adding $100 \mathrm{ppm}$ ferrocene $\left(\mathrm{ME}_{\mathrm{NT}}(2.1,100): \tau=7.9 \mathrm{~s}\right)$. However, $\mathrm{ME}_{\mathrm{NT}}$

$8(4.2,100)$ exhibited a longer extinguishing time of approximately $9 \mathrm{~s}$, and $\operatorname{ME}_{\mathrm{NT}}(10.5,100)$ was

9 unable to extinguish pool fires, thereby implying that the flammability of $10.5 \mathrm{wt} \%$ oil surpasses the

10 suppression efficiency of $100 \mathrm{ppm}$ ferrocene.

11 Interestingly, even though $\mathrm{ME}_{\mathrm{NT}}(10.5,100)$ contained no less than $36.8 \mathrm{wt} \% \mathrm{NT}$, it was unable to

12 extinguish the pool fire. Thus, the use of NT as a surfactant eliminates the need to consider the

13 influence of the surfactant on the suppression efficiency.

\subsubsection{Influence of ferrocene concentration on extinguishing time}

16 As noted above, measuring the spray droplet size as well as the oil-droplet diameter in

17 microemulsions is of great importance for evaluating the fire-suppression efficiency. Table 3 gives the

18 Sauter mean diameters of the spray droplets $\left(S M D_{\mathrm{m}}\right)$ from an aqueous NT solution, $\mathrm{ME}_{\mathrm{NT}}(2.1,0)$, 
$1 \operatorname{ME}_{\mathrm{NT}}(2.1,100)$, and $\operatorname{ME}_{\mathrm{NT}}(2.1,1000)$. There were no significant differences in the $S M D_{\mathrm{m}}$ values

2 among these samples, which clearly indicates that the oil and ferrocene concentrations negligibly

3 affect the spray droplet size. This is probably because the concentrations of n-octane and ferrocene

4 were too low to affect the Sauter mean diameters (n-octane: $2.1 \mathrm{wt} \%$ and ferrocene: $0-1,000 \mathrm{ppm}$ ).

5 Together with the result given in subsection 4.1.1, which showed that the surfactant had little

6 suppression effect, the above finding enables us to directly investigate the influence of the ferrocene

7 concentration on the extinguishing efficiency.

Fig. 9 presents the average extinguishing times for the microemulsions containing $2.1 \mathrm{wt} \% \mathrm{n}$ -

9 octane, NT, and 0-1000 ppm ferrocene; $R_{\mathrm{NT}}$ was set to 3.5. In this figure, the extinguishing times for

10 an NT soln. and a wet chemical agent (an aqueous solution of $45 \mathrm{wt} \%$ potassium carbonate) are also

11 shown for reference. We confirmed that pure water mist cannot extinguish the pool fire, whereas the

12 NT. soln. is able to suppress it ( $\tau=14.7 \mathrm{~s}, \sigma=5.9 \mathrm{~s}$ ) under the same experimental conditions (i.e.,

13 flow rate, temperature, pool-fire size). The microemulsion without ferrocene (i.e., $\left.\operatorname{ME}_{\mathrm{NT}}(2.1,0)\right)$ had an extinguishing time of $20.6 \mathrm{~s}$ with a standard deviation of $5.1 \mathrm{~s}$; the increase in the extinguishing time relative to the NT. soln. arose from the flammability of the oil. However, the extinguishing time steeply decreased at a ferrocene concentration of $100 \mathrm{ppm}\left(\operatorname{ME}_{\mathrm{NT}}(2.1,100): \tau=7.9 \mathrm{~s}, \sigma=3.5\right.$ s), i.e.,

17 the extinguishing time of $\mathrm{ME}(2.1,100)$ is reduced by a factor of 2.6 compared with that of $\mathrm{ME}_{\mathrm{NT}}(2.1$, 
1 500), $\mathrm{ME}_{\mathrm{NT}}(2.1,750)$, and $\operatorname{ME}_{\mathrm{NT}}(2.1,1,000)$, respectively. The wet chemical agent had an

2 extinguishing time of $8.9 \mathrm{~s}$ [17]. This result clearly indicated that the microemulsions exhibit a higher

3 suppression efficiency than the conventional fire suppressant.

A one-way analysis of variance (ANOVA) was conducted to test for differences in the extinguishing times among the microemulsions: $\operatorname{ME}_{\mathrm{NT}}(2.1,0), \mathrm{ME}_{\mathrm{NT}}(2.1,100), \mathrm{ME}_{\mathrm{NT}}(2.1,250)$, $\operatorname{ME}_{\mathrm{NT}}(2.1,500), \mathrm{ME}_{\mathrm{NT}}(2.1,750)$, and $\mathrm{ME}_{\mathrm{NT}}(2.1,1,000)$. In this work, differences were considered to be significant if the $p$-value was smaller than 0.05 . The one-way ANOVA revealed significant effects of the ferrocene concentration on the extinguishing time $(F=40.80, p<0.001)$. Post hoc tests clearly indicated that $\mathrm{ME}_{\mathrm{NT}}(2.1,0)$ exhibited a significantly longer extinguishing time than $\operatorname{ME}_{\mathrm{NT}}(2.1,100)-$ $\operatorname{ME}_{\mathrm{NT}}(2.1,1000)(p<0.001)$. Furthermore, post hoc tests also revealed that there were no significant differences in the extinguishing times among $\operatorname{ME}_{\mathrm{NT}}(2.1,100)-\mathrm{ME}_{\mathrm{NT}}(2.1,1,000)$. This suggests that the ferrocene concentration required in the microemulsion system is less than $\sim 100 \mathrm{ppm}$, which is a great practical advantage in industrial processes.

The present work clearly demonstrated that the new $\mathrm{O} / \mathrm{W}$ microemulsion-based fire suppressants would be effective on class B fires; further work regarding class A fires is required. Although ferrocene possesses an HMIS and NFPA rating of 2 for health (i.e., it may be harmful if inhaled or absorbed, Sigma-Aldrich safety data sheet, product number F408), the new fire suppressants developed in this work contain ferrocene concentrations of the order of $\mathrm{ppm}$, thus indicating that health and 
1 environmental risks would be low when the suppressant is used with a handheld fire extinguisher.

\section{5. Conclusions}

In this work, new oil-in-water emulsions containing ferrocene $(0-1,000 \mathrm{ppm})$ and four surfactants

(SN, OE, TX, and NT) were prepared by homogenizing n-octane solutions of ferrocene and aqueous

surfactant solutions at room temperature. Four emulsion parameters were then characterized: emulsion stability, emulsion droplet size, flammability, and fire-suppression capability. The main results obtained from this study can be summarized as follows:

(1) Emulsion stability experiments demonstrated that phase separation rapidly occurred for the $\mathrm{O} / \mathrm{W}$ emulsions containing $\mathrm{SN}$ or OE, whereas no phase separation was observed for at least 25 months for the transparent $\mathrm{O} / \mathrm{W}$ emulsions containing $\mathrm{TX}$ or $\mathrm{TN}$ with $R_{\mathrm{TX}} \geq 5.0$ or $R_{\mathrm{NT}} \geq 3.5$, respectively. the thermodynamically stable emulsions are "microemulsions."

(2) Droplet-size measurements also demonstrated that, in the ferrocene concentration range $0-1,000$ ppm, no significant differences were observed in terms of the Sauter mean diameter between the oil droplets in the microemulsions and their spray droplets, thus allowing a direct comparison of 
their fire-extinguishing efficiency.

2 (3) Flash-point measurements confirmed that no microemulsions tested in this study ignited below

3

4

5

6

7

8

9

10

11 $93{ }^{\circ} \mathrm{C}$.

(4) Suppression trials involving pool fires clearly demonstrated that ferrocene-containing microemulsions exhibit a higher suppression efficiency than a conventional wet chemical agent in the 100-1000 ppm ferrocene concentration range. Furthermore, one-way ANOVA and post hoc tests revealed that there are no significant differences in the extinguishing times among $\mathrm{ME}_{\mathrm{NT}}(2.1$, $100)-\mathrm{ME}_{\mathrm{NT}}(2.1,1000)$, which means that the ferrocene concentration in the microemulsion system need not be more than $100 \mathrm{ppm}$.

In conclusion, even though $2.1 \mathrm{wt} \%$ flammable oil (i.e., n-octane) exists in the oil-in-water microemulsions, ferrocene-containing microemulsions exhibit high pool-fire extinguishing efficiency, due to flame inhibition by ferrocene. The findings presented in this paper open new avenues for developing novel, phosphorus-free microemulsion-based fire suppressants.

\section{Acknowledgments}

This work was supported both by Yokohama Academic Foundation (grant number 578) and by JSPS KAKENHI Grant Number JP17K12987 to Y.K. We gratefully acknowledge the Kanagawa 
1 Industrial Technology Center for conducting the size distribution measurements by dynamic light

2 scattering. The immersion measurements were performed at the Instrumental Analysis Center of 3 Yokohama National University.

4

5

6 References

7

8 [1] M. Krasnyansky, Remote extinguishing of large fires with powder aerosols, Fire Mater. 30 (2006)

$9 \quad 371-382$.

10 [2] C.T. Ewing, F.R. Faith, J.B. Romans, J.T. Hughes, H.W. Carhart, Flame extinguishment 11 properties of dry chemicals: extinction weights for small diffusion pan fires and additional evidence for flame extinguishment by thermal mechanisms, J. Fire Prot. Eng. 4 (1992) 35-51.

13 [3] L. Reijnders, Phosphorus resources, their depletion and conservation, a review, Resour. Conserv. Recycl. 93 (2014) 32-49.

15 [4] U.S. Geological Survey, U.S. Department of the Interior <https://www.usgs.gov/> 2016, $16 \quad$ (accessed 14.02.17).

17 [5] Y. Zhang, E. Desmidt, A. Van Looveren, L. Pinoy, B. Meesschaert, B. Van der Bruggen, 18 Phosphate separation and recovery from wastewater by novel electrodialysis, Environ. Sci. 
2 [6] G. Grant, J. Brenton, D. Drysdale, Fire supression by water sprays, Prog. Ener. Combust. Sci. 26 (2000) 79-130.

[7] G. LeFort, A.W. Marshall, M. Pabon, Evaluation of surfactant enhanced water mist performance, Fire Technol. 45 (2009) 341-354.

[8] J.S. Rosen, M.D. Szkutak, S.M. Jaskolka, M.S. Connolly, K.A. Notarianni, Engineering performance of water mist fire protection systems with antifreeze, J. Fire Prot. Eng. 23 (2013) $190-225$.

[9] G.T. Linteris, Suppression of cup-burner diffusion flames by super-effective chemical inhibitors and inert compounds, in: Halon Options Technical Working Conference, 2001, pp. $187-196$.

[10] Y. Koshiba, Y. Takahashi, H. Ohtani, Flame suppression ability of metallocenes (nickelocene, cobaltocene, ferrocene, manganocene, and chromocene), Fire Saf. J. 51 (2012) 10-17.

[11] S.K. Sharma, N.K. Saxena, A.K. Gupta, Flame retardant smoke suppressants for poly(vinyl chloride), J. Appl. Fire Sci. 17 (2007-2008) 143-165.

[12] T. Hirosawa, C.-J. Sung, Z. Yang, A. Joshi, H. Wang, Effect of ferrocene addition on sooting limits in laminar premixed ethylene-oxygen-argon flames. Combust. Flame 139 (2004) 288-299. 
based polyamides with improved solubility, React. Funct. Polym. 67 (2007) 883-892.

2 [14] R.M. Garrett, C. Guénette, C.E. Haith, R.C. Prince, Pyrogenic polycyclic aromatic hydrocarbons in oil burn residues, Environ. Sci. Technol. 34 (2000) 1934-1937.

[15] Y. Koshiba, S. Okazaki, H. Ohtani, Experimental investigation of the fire extinguishing capability of ferrocene-containing water mist, Fire Saf. J. 83 (2016) 90-98.

6 [16] Y. Koshiba, K. Iida, H. Ohtani, Fire extinguishing properties of novel ferrocene/surfynol 465 dispersions, Fire Saf. J. 72 (2015) 1-6.

[17] Y. Koshiba, T. Tomita, H. Ohtani, Ferrocene-containing emulsion-based fire-extinguishing agents, Fire Sci. Technol. 36 (2017) 1-9.

[18] M.L. Klossek, D. Tourand, W. Kunz, Highly and fully water dilutable sustainable microemulsions with dibasic esters as oil phase, ACS Sustain. Chem. Eng. 1 (2013) 603-610.

[19] C.T. Ewing, F.R., Faith, J.B. Romans, C.W., Siegmann, R.J. Ouellette, J.T., Hughes, H.W., Cathart, Extingishing class B fires with dry chemicals: scaling studies, Fire Technol. 31 (1995) $17-43$.

[20] M.E. Vaquero, J. Barriuso, M.J. Martínez, A. Prieto, Properties, structure, and applications of microbial sterol esterases, Appl. Microbiol. Biotechnol. 100 (2016) 2047-2061. 
in natural milk environment, Food Anal. Methods 9 (2016) 646-655.

2 [22] T. Oku, Y. Ohishi, A. Suzuki, Effects of antimony addition to perovskite-type $\mathrm{CH}_{3} \mathrm{NH}_{3} \mathrm{PbI}_{3}$

3 photovoltaic devices, Chem. Lett. 45 (2016)134-136.

[23] C.D. Ampatidis, E.-M.A. Varka, T.D. Karapantsios, Interfacial activity of amino acid-based glycerol ether surfactants and their performance in stabilizing $\mathrm{O} / \mathrm{W}$ cosmetic emulsions, Colloid Surf. A Physicochem. Eng. Asp. 460 (2014) 176-183.

[24] P. Paximada, E. Tsouko, N. Kopsahelis, A.A. Koutinas, I. Mandala, Bacterial cellulose as stabilizer of o/w emulsions, Food Hydrocolloids 53 (2016) 225-232.

[25] K. Holmberg., B. Jönsson, B. Kronberg, B. Lindman, Surfactants and polymers in aqueous solution, second ed. John Wiley \& Sons, Ltd, Chichester, 2006.

[26] A.R. Tehrani-Bagha, A. Viladot, K. Holmberg, L. Nordstierna, An ouzo emulsion of toluene in water characterized by NMR diffusometry and static multiple light scattering, Colloid Surf. A Physicochem. Eng. Asp. 494 (2016) 81-86.

[27] K. Sakai, A. Fukushima, T. Misono, T. Endo, K. Sakamoto, H. Sakai, M. Abe, Emulsification by phosphorylcholine-type gemini amphiphile as active interfacial modifier, Chem. Lett. 44 (2014) 247-249.

[28] T.T.Q. Phan, T.T. Le, D. Van de Walle, P. Van der Meeren, K. Dewettinck, Combined effects of milk fat globule membrane polar lipids and protein concentrate on the stability of oil-in-water 
emulsions, Int. Dairy J. 52 (2016) 42-49.

[29] K. Nakaya, H. Ushio, S. Matsukawa, M. Shimizu, T. Ohshima, Effects of droplet size on the oxidative stability of oil-in-water emulsions, Lipids 40 (2005) 501-507.

[30] P.S. Denkova. S. Tsholakova, N.D. Denkov, K.D. Danov, B. Campbell, C. Shawl, D. Kim, Evaluation of the precision of drop-size determination in oil/water emulsions by low-resolution NMR spectroscopy, Langmuir 20 (2004) 11402-11413.

[31] D.A. Crowl, J.F. Louvar, Chemical Process Safety, third ed. Pearson Education, Boston, p. 654, 2011.

[32] JIS 2265-1, Determination of flash point-Part 1: tag closed cup method. Tokyo, 2006.

[33] E.T. Hurlburt, T.J. Hanratty, Measurement of drop size in horizontal annular flow with the immersion method, Exp. Fluids 32 (2002) 692-699.

[34] G.T. Linteris, M.D. Rumminger, V.I. Babushok, Catalytic inhibition of laminar flames by transition metal compounds, Prog. Ener. Combust. Sci. 34 (2008) 288-329.

[35] J.C.Y. Lee, J.D. Felske, N. Ashgriz, Flame propagation across gelled alkane-in-water emulsions, Spill Sci. Technol. Bull. 8 (2003) 391-398. 
1 The Sauter mean diameters of oil droplets $\left(\mathrm{SMD}_{\mathrm{o}}\right)$ in the $\mathrm{O} / \mathrm{W}$ microemulsions containing $2.1 \mathrm{wt} \% \mathrm{n}$ -

2 octane, $0-1000$ ppm ferrocene, and a surfactant: NT or TX.

3

4 Table 2

5 Samples tested in the suppression trials.

6

7 Table 3

8 The Sauter mean diameters of spray droplets $\left(\mathrm{SMD}_{\mathrm{m}}\right)$ from an aqueous NT solution and

9 microemulsions. For the microemulsions, $R_{\mathrm{NT}}$ is 3.5 . The aqueous NT solution contained $7.35 \mathrm{wt} \%$

10 NT

11

12

13

14

15

16

\section{$17 \quad$ Figure captions}

18 Figure 1 
1 Trend in market prices of phosphate rock from 2000 to 2016 (adapted from [4]).

$3 \quad$ Figure 2

4 Chemical structures of (a) ferrocene and the surfactants: (b) Surfynol 465 (SN, $m+n=20$ ), (c) Olfin

5 E1020 (OE, $m+n=30)$, (d) Noigen TDS-80 (NT, $\left.\mathrm{R}=\mathrm{CO}\left(\mathrm{CH}_{2}\right)_{16} \mathrm{CH}_{3}\right)$, and (e) Triton X-100 (TX, $m$

$6=10)$.

7

$8 \quad$ Figure 3

9 Schematic of the experimental apparatus used for the suppression trials.

11 Figure 4

12 Schematic model of the suppression mechanism of ferrocene-containing O/W microemulsions.

14 Figure 5

15 Phase separation for the $\mathrm{O} / \mathrm{W}$ emulsions containing $1000 \mathrm{ppm}$ ferrocene and the surfactants as a

16 function of storage time: (a) surfactant $=\mathrm{NT}$, and (b) surfactant $=\mathrm{TX}$. The squares, circles, triangles,

17 stars, and pentagons denote $R=2.0,3.0,3.5,4.0$, and 5.0, respectively. 
1 Figure 6

2 Photographs of (a) $\mathrm{O} / \mathrm{W}$ microemulsions containing $2.1 \mathrm{wt} \% \mathrm{n}$-octane, 0-750 ppm ferrocene, and NT

$3 \quad\left(R_{\mathrm{NT}}=3.5\right.$; left Petri dish: $100 \mathrm{ppm}$ ferrocene, $\operatorname{ME}_{\mathrm{NT}}(2.1,100)$; center Petri dish: 500 ppm ferrocene,

$4 \mathrm{ME}_{\mathrm{NT}}(2.1,500)$; right Petri dish: $750 \mathrm{ppm}$ ferrocene, $\left.\mathrm{ME}_{\mathrm{NT}}(2.1,750)\right)$, (b) $\mathrm{O} / \mathrm{W}$ microemulsions

5 containing $2.1 \mathrm{wt} \%$ n-octane, $0-1000 \mathrm{ppm}$ ferrocene, and TX $\left(R_{\mathrm{TX}}=5.0\right.$; left Petri dish: $100 \mathrm{ppm}$

6 ferrocene, $\operatorname{ME}_{\mathrm{TX}}(2.1,100)$; center Petri dish: 500 ppm ferrocene, $\operatorname{ME}_{\mathrm{TX}}(2.1,500)$; right Petri dish:

$71000 \mathrm{ppm}$ ferrocene, $\left.\mathrm{ME}_{\mathrm{TX}}(2.1,1000)\right)$, and (c) an $\mathrm{O} / \mathrm{W}$ macroemulsion containing $2.1 \mathrm{wt} \% \mathrm{n}$-octane,

$8100 \mathrm{ppm}$ ferrocene, and NT $\left(R_{\mathrm{NT}}=1.0\right)$. Note that the emulsions shown in (a) and (b) were

9 photographed 25 months after preparation, and the emulsion presented in (c) was photographed

10 immediately after preparation because of its instability.

$12 \quad$ Figure 7

13 Typical photographs of fire suppression trials: (a) pure water, after $0 \mathrm{~s}$, (b) pure water, after $15 \mathrm{~s}$, (c)

14 pure water, after $30 \mathrm{~s}$, (d) pure water, after $45 \mathrm{~s}$, (e) $\mathrm{O} / \mathrm{W} \mathrm{ME}_{\mathrm{NT}}\left(2.1,750\right.$ ), after $0 \mathrm{~s}$, (f) $\mathrm{O} / \mathrm{W} \mathrm{ME}_{\mathrm{NT}}$

$15(2.1,750)$, after $2.5 \mathrm{~s},(\mathrm{~g}) \mathrm{O} / \mathrm{W} \mathrm{ME}_{\mathrm{NT}}(2.1,750)$, after $5.0 \mathrm{~s}$, and (h) $\mathrm{O} / \mathrm{W} \mathrm{ME}_{\mathrm{NT}}(2.1,750)$, after $5.4 \mathrm{~s}$.

$17 \quad$ Figure 8

18 Influence of oil concentration on the extinguishing times of the microemulsions. Error bars indicate 
1 standard deviations.

2

$3 \quad$ Figure 9

4 Influence of ferrocene concentration on extinguishing times (open bar: aqueous NT solution, gray bar:

5 microemulsion not containing ferrocene, yellow bars: ferrocene-containing microemulsions, and

6 striped bar: wet chemical agent containing $45 \mathrm{wt} \%$ potassium carbonate). Error bars indicate standard

7 deviations. 
Table 1

\begin{tabular}{|c|c|c|}
\hline Microemulsion $^{\mathrm{a}}$ & $R^{\mathrm{b}}$ & $S M D_{\mathrm{o}}(\mathrm{nm})$ \\
\hline $\operatorname{ME}_{\mathrm{NT}}(2.1,0)$ & 3.5 & 11.0 \\
\hline $\operatorname{ME}_{\mathrm{NT}}(2.1,100)$ & 3.5 & 11.3 \\
\hline $\mathrm{ME}_{\mathrm{NT}}(2.1,500)$ & 3.5 & 12.4 \\
\hline $\operatorname{ME}_{\mathrm{NT}}(2.1,1000)$ & 3.5 & 14.2 \\
\hline $\operatorname{ME}_{\mathrm{TX}}(2.1,0)$ & 5.0 & 12.0 \\
\hline $\operatorname{ME}_{T X}(2.1,100)$ & 5.0 & 10.9 \\
\hline $\operatorname{ME}_{T X}(2.1,1000)$ & 5.0 & 7.9 \\
\hline \multicolumn{3}{|c|}{$\begin{array}{l}\text { a: As described in the text, the microemulsion containing } \mathrm{NT}, x \text { - } \\
\mathrm{wt} \% \text { oil, and } y \text {-ppm ferrocene is referred to as "ME } \mathrm{ME}_{\mathrm{NT}}(x, y) \text {," while } \\
\text { the corresponding microemulsion containing } \mathrm{TX} \text { is referred to as }\end{array}$} \\
\hline
\end{tabular}


Table 2

\begin{tabular}{lccc}
\hline Sample & n-octane concentration $(\mathrm{wt} \%)$ & Ferrocene concentration $(\mathrm{ppm})$ & $\mathrm{K}_{2} \mathrm{CO}_{3}$ concentration $(\mathrm{wt} \%)$ \\
\hline NT soln. ${ }^{\mathrm{a}}$ & 0 & 0 & 0 \\
$\mathrm{ME}_{\mathrm{NT}}(2.1,0)$ & 2.1 & 0 & 0 \\
$\mathrm{ME}_{\mathrm{NT}}(2.1,100)$ & 2.1 & 100 & 0 \\
$\mathrm{ME}_{\mathrm{NT}}(4.2,100)$ & 4.2 & 100 & 0 \\
$\mathrm{ME}_{\mathrm{NT}}(10.5,100)$ & 10.5 & 100 & 0 \\
$\mathrm{ME}_{\mathrm{NT}}(2.1,250)$ & 2.1 & 250 & 0 \\
$\mathrm{ME}_{\mathrm{NT}}(2.1,500)$ & 2.1 & 500 & 0 \\
$\mathrm{ME}_{\mathrm{NT}}(2.1,750)$ & 2.1 & 750 & 0 \\
$\mathrm{ME}_{\mathrm{NT}}(2.1,1000)$ & 2.1 & 1000 & 0 \\
$\mathrm{Wet}_{\text {chemical }}$ & 0 & 0 & 45 \\
\hline
\end{tabular}

Note: The value $R_{\mathrm{NT}}$ is set to 3.5. a: Aqueous solution of NT. 
Table 3

\begin{tabular}{ll} 
Sample & $S M D_{\mathrm{m}}(\mu \mathrm{m})$ \\
\hline NT soln. & 54 \\
$\operatorname{ME}_{\mathrm{NT}}(2.1,0)$ & 42 \\
$\operatorname{ME}_{\mathrm{NT}}(2.1,100)$ & 44 \\
$\operatorname{ME}_{\mathrm{NT}}(2.1,1000)$ & 43 \\
\hline
\end{tabular}


Figure 1

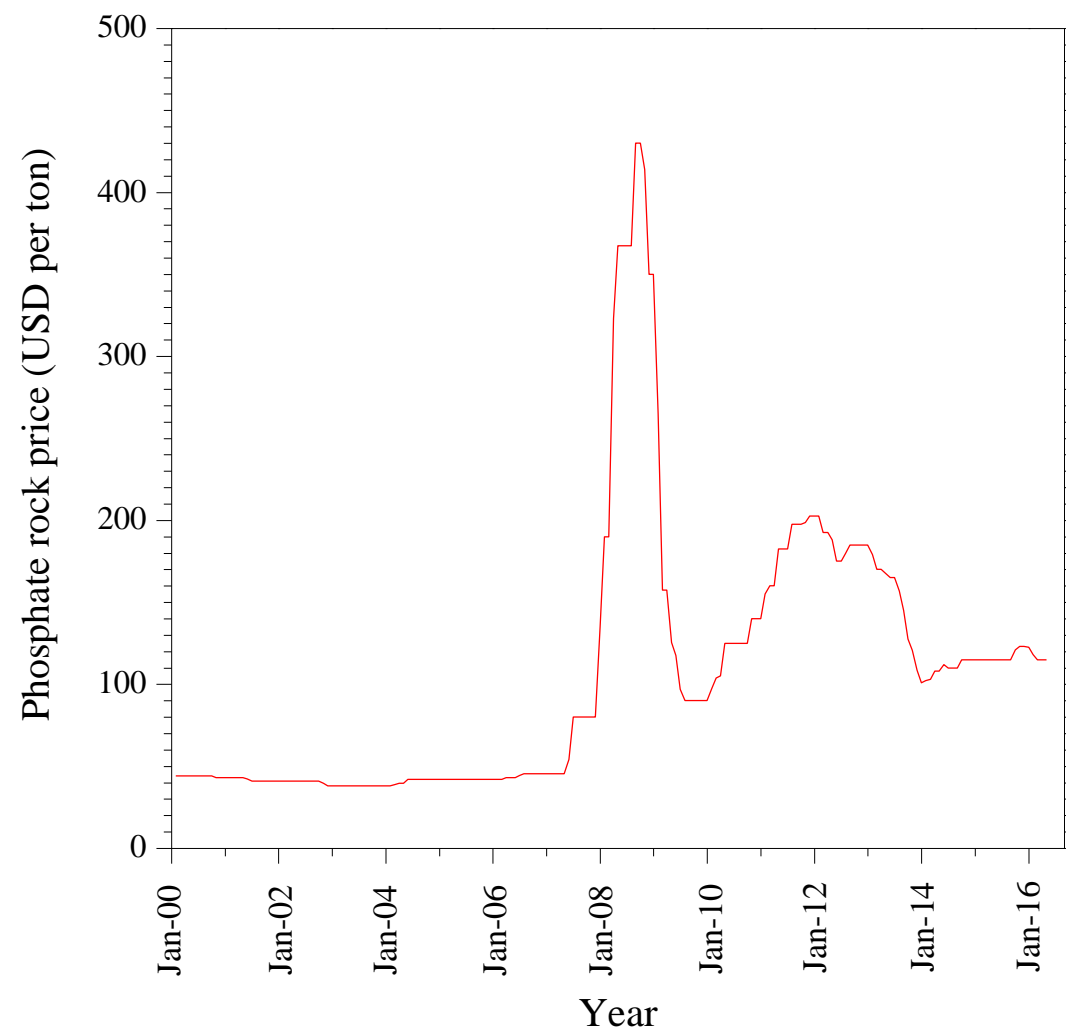


Figure 2

a

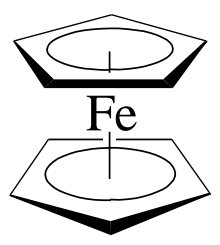

d<smiles>[R]OCC(C)(C)O</smiles>

b, c

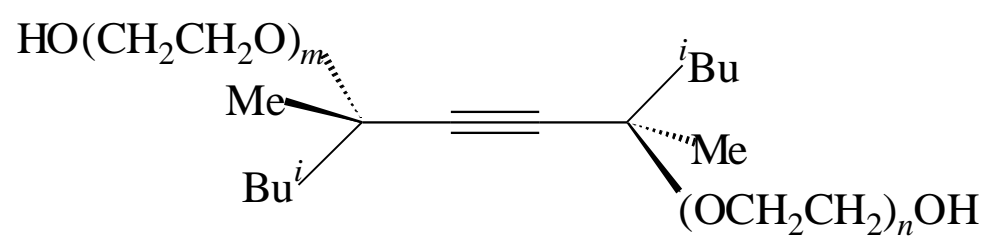

e<smiles>CC(C)(O)CC(C)(C)OCc1ccc(C(C)(C)CBr)cc1</smiles> 
Figure 3

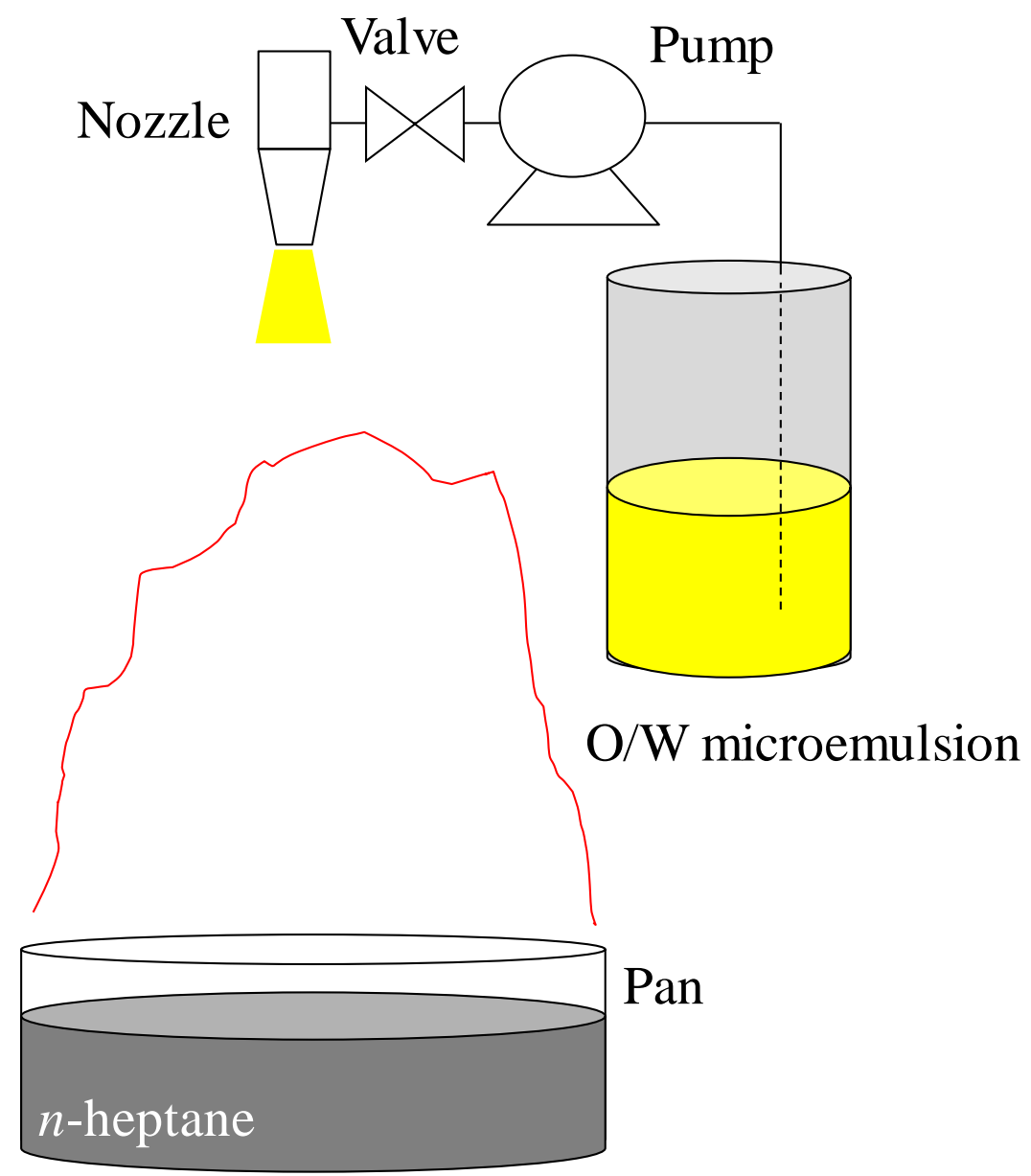




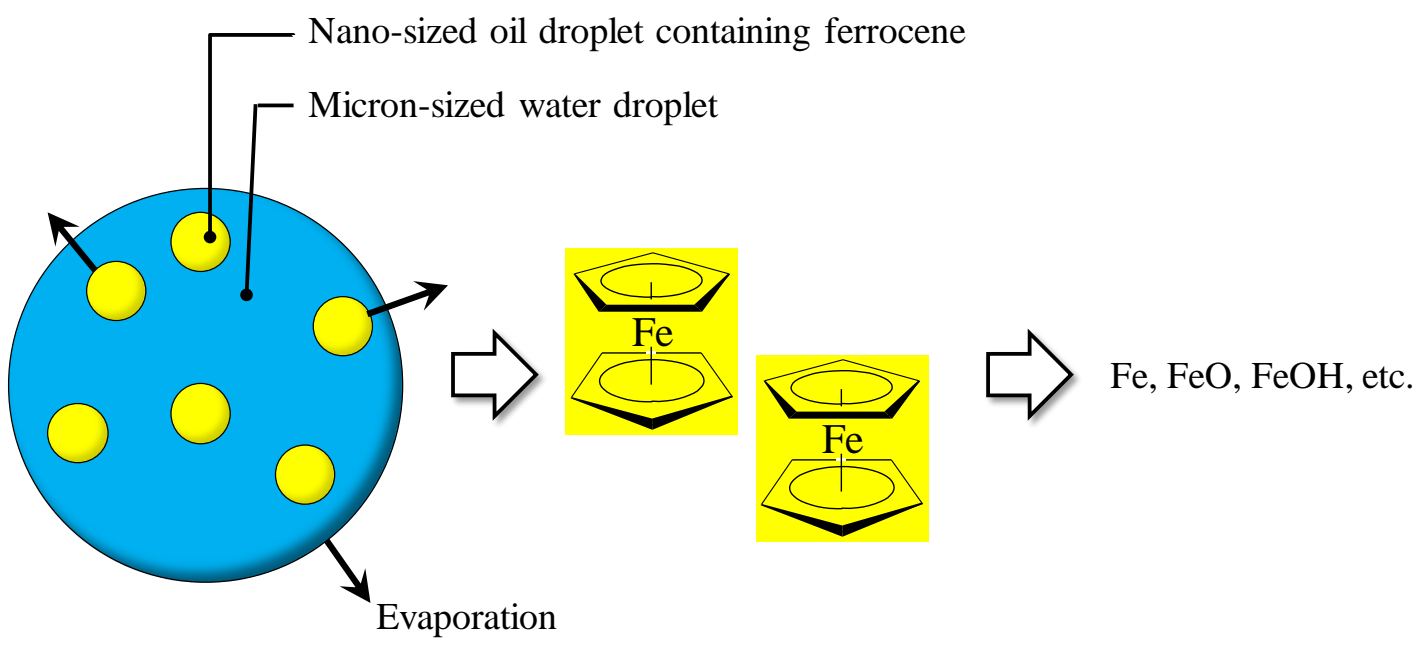

Spray droplet

Release of Ferrocene molecules
Formation of inhibiting iron species 
Figure 5

a

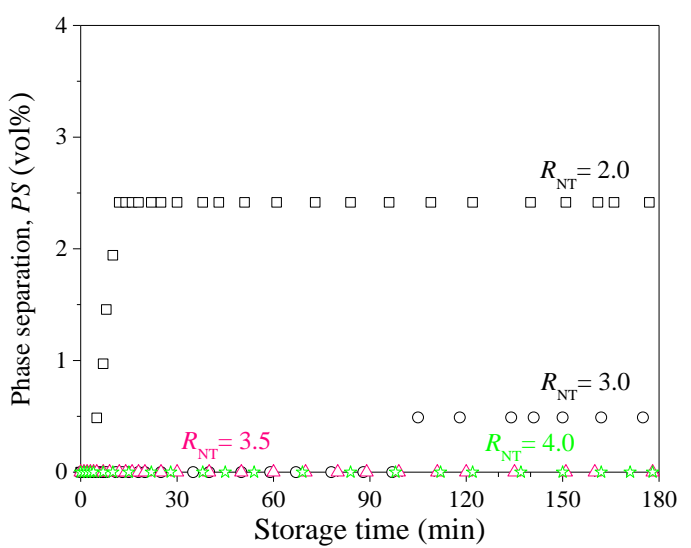

b

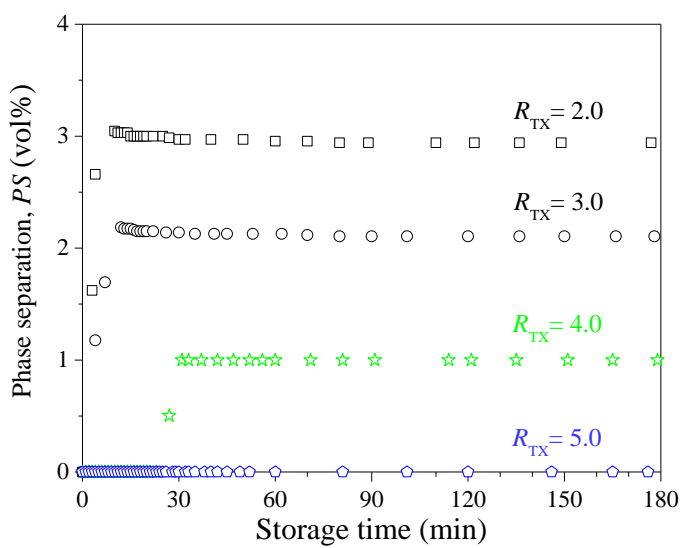


Figure 6
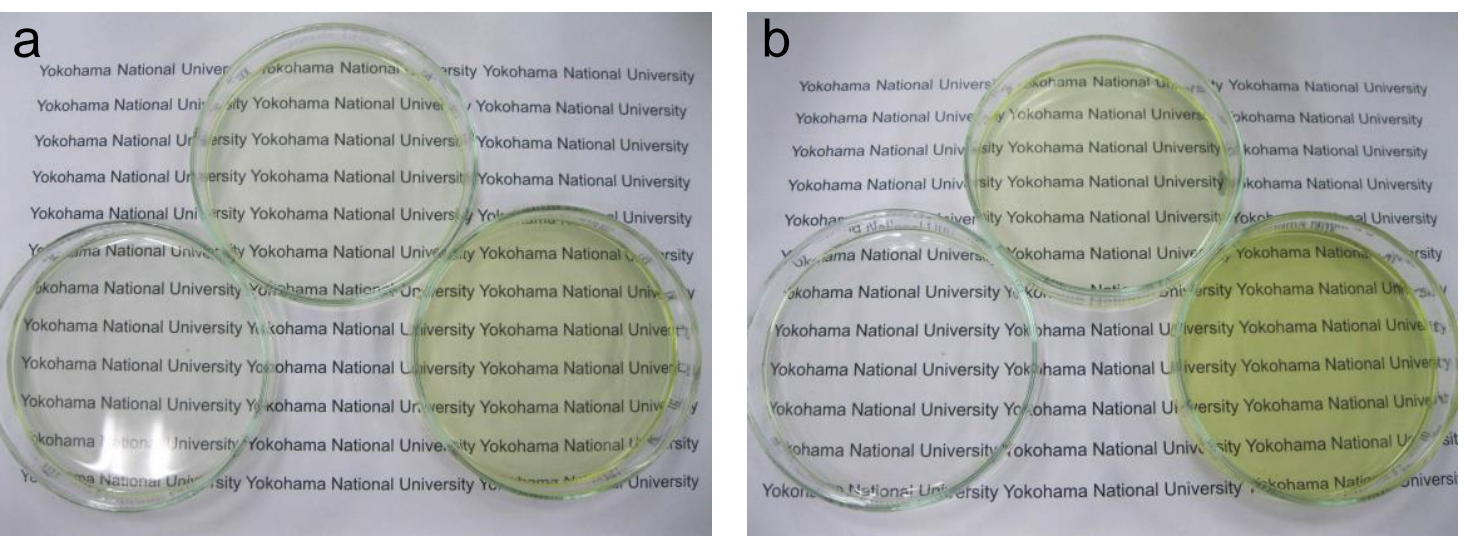

C

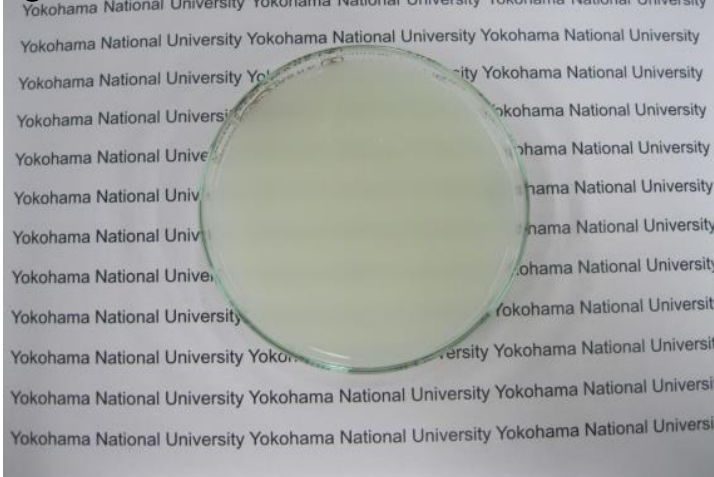


Figure 7
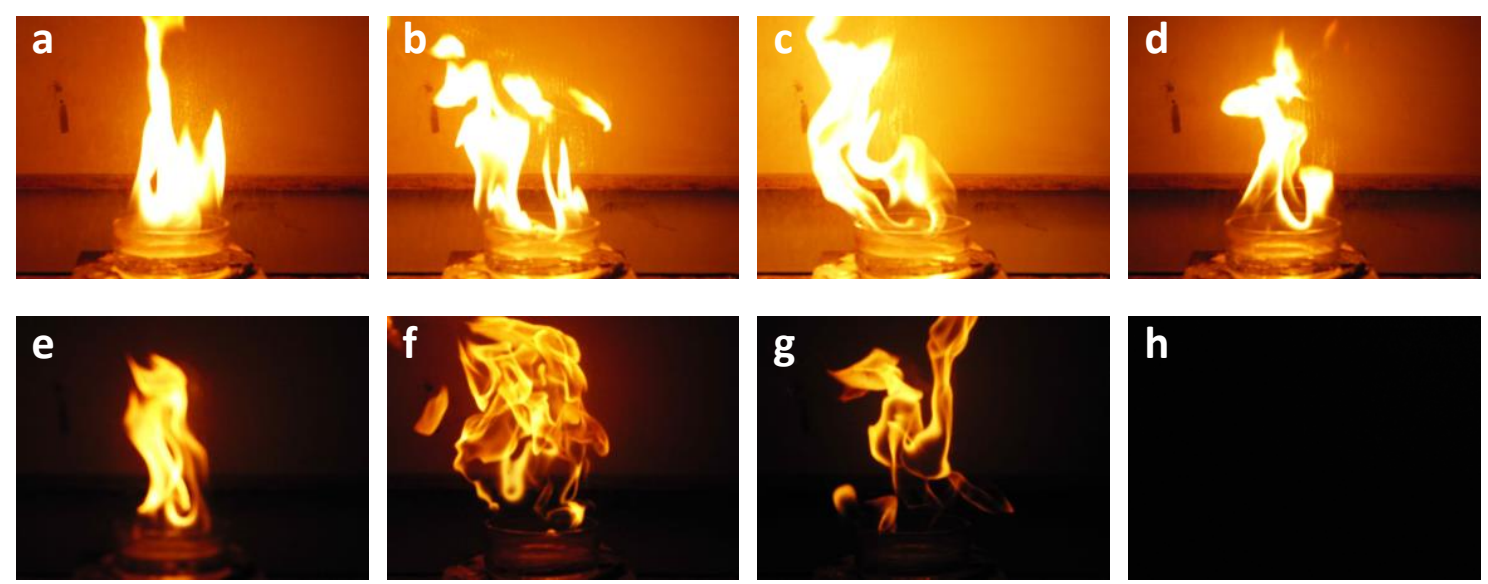

h 
Figure 8

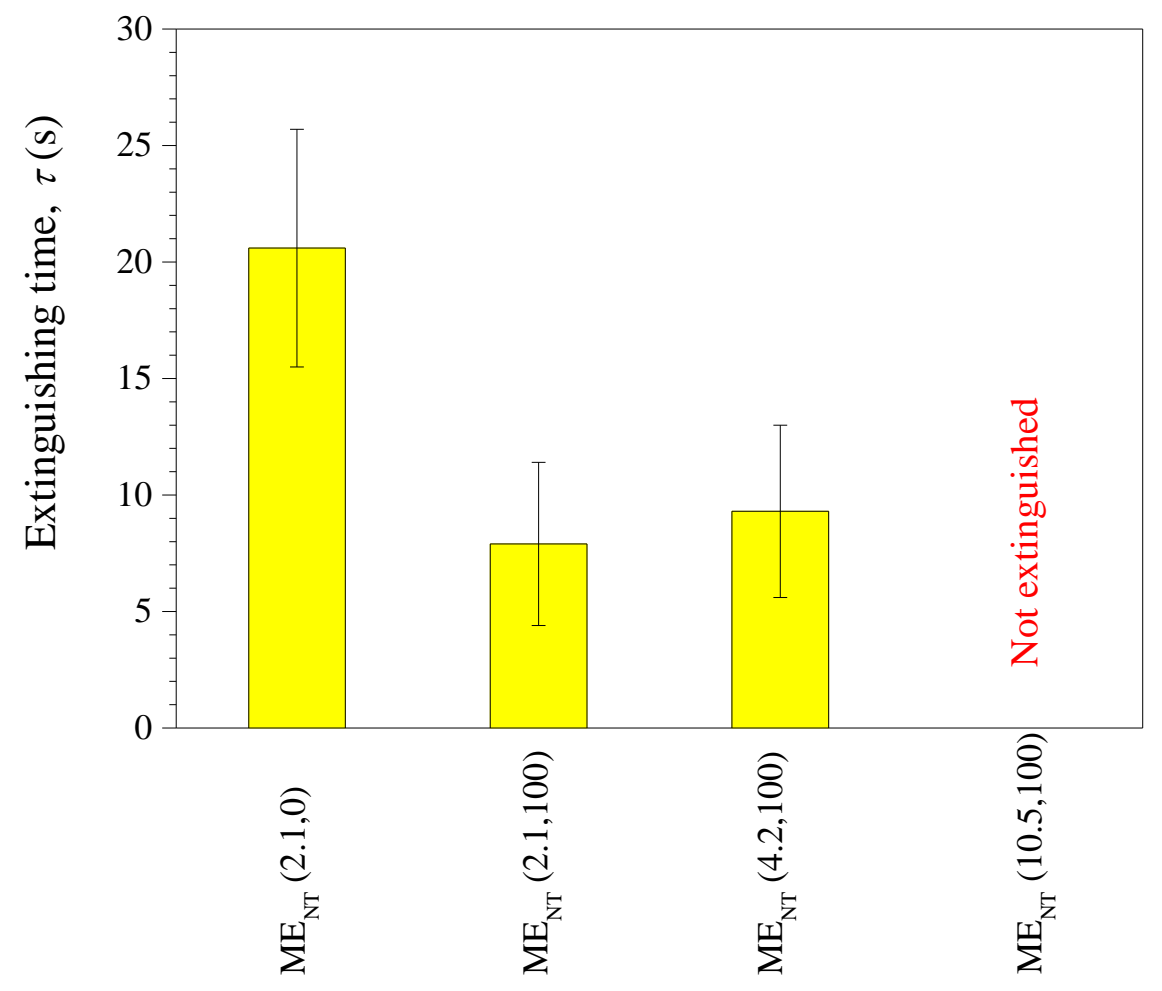


Figure 9

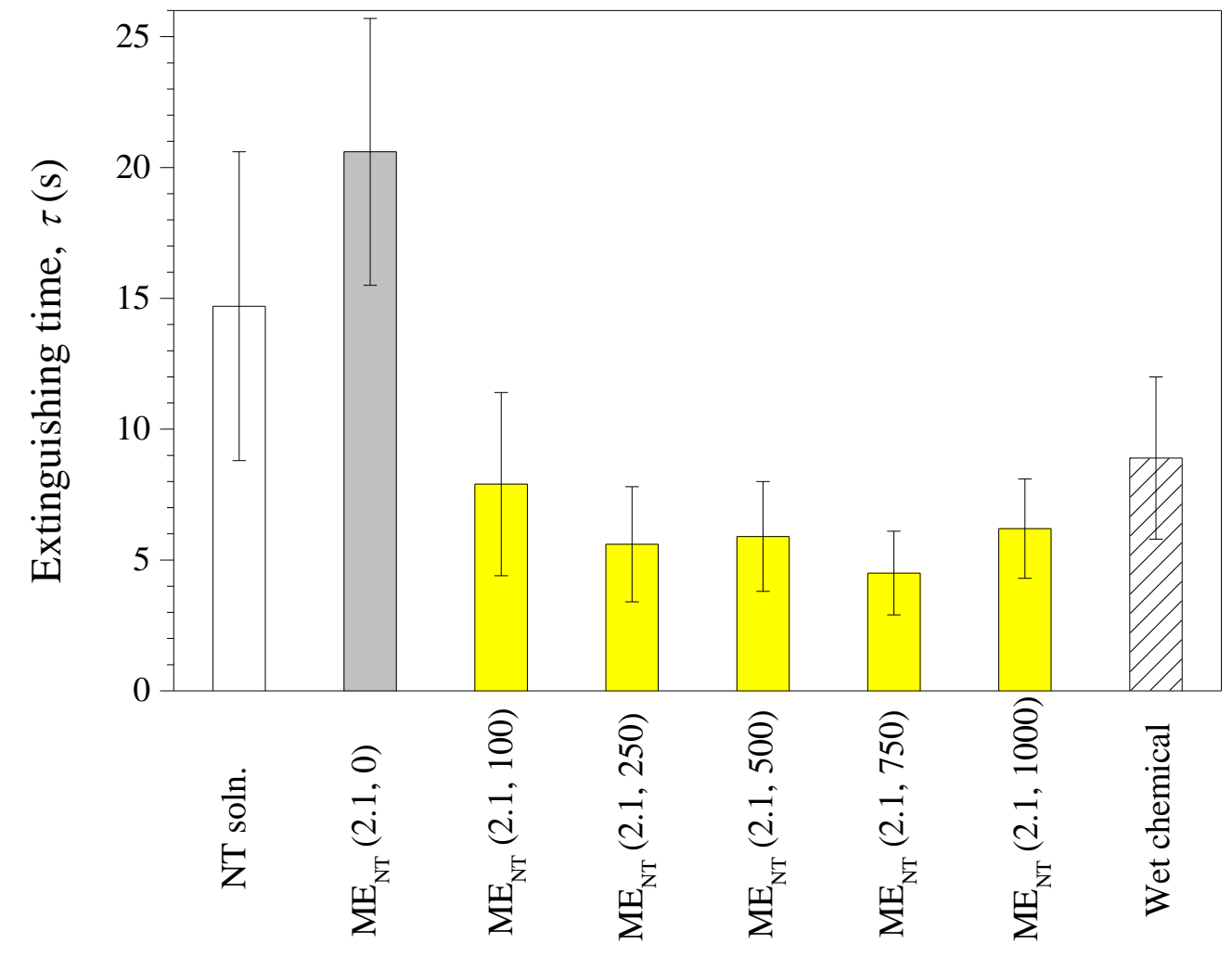




\section{Highlights}

- Thermodynamically stable ferrocene-containing microemulsions are prepared.

- Ferrocene-containing microemulsions exhibit high fire-suppression efficiency.

- The suppression capability depends on the concentrations of ferrocene and oil. 